Research Article

\title{
Supplier Selection of Shipbuilding Enterprises Based on Intuitionistic Fuzzy Multicriteria Decision
}

\author{
Xiang Ziquan (D), Yang Jiaqi, Muhammad Hamza Naseem (D, Xiang Zuquan (D), \\ and Liang Xueheng
}

School of Transportation, Wuhan University of Technology, Wuhan 430063, China

Correspondence should be addressed to Xiang Ziquan; xiangziquan@whut.edu.cn

Received 30 April 2021; Revised 26 June 2021; Accepted 13 July 2021; Published 22 July 2021

Academic Editor: Edyta Kucharska

Copyright ( 2021 Xiang Ziquan et al. This is an open access article distributed under the Creative Commons Attribution License, which permits unrestricted use, distribution, and reproduction in any medium, provided the original work is properly cited.

\begin{abstract}
With the increasingly fierce competition in the global shipbuilding industry, shipbuilding enterprises need to maintain competitiveness and cope with rapid changes. In this case, shipbuilding enterprises need to establish effective supply chain management. Among them, choosing the right supplier is one of the most critical activities. The supplier selection of shipbuilding enterprises is considered a complex multicriteria decision-making (MCDM) problem that attracts much attention due to intuitionistic fuzzy sets to deal with possible imprecision and fuzziness in real life. Based on this, this paper proposes a new method based on the intuitionistic fuzzy SWARA (stepwise weight assessment ratio analysis) and COPRAS (complex proportional assessment) method to select shipbuilding enterprise suppliers which is a new research area. First of all, different weights are given to each expert evaluation result according to their position, educational background, and working years. The supplier index's weight is determined based on the intuitionistic fuzzy SWARA method, and it is easy to understand and operate. The ranking of suppliers is determined by the intuitionistic fuzzy COPRAS method. This method considers all kinds of uncertainties and evaluates the utility index and the cost index of alternative suppliers. Finally, taking a shipbuilding enterprise as an example, applying the intuitionistic fuzzy SWARA-COPRAS method is illustrated. Compared with other methods and sensitivity analysis, it shows that the intuitionistic fuzzy multicriteria decision-making method is effective and stable in shipbuilding enterprises.
\end{abstract}

\section{Introduction}

In today's fiercely competitive environment, shipbuilding companies are facing many challenges. Supplier selection is one of the most important activities for shipbuilding companies. The issue of supplier selection for shipbuilding companies is a critical area in the shipbuilding supply chain. The allocation of orders to multiple suppliers by enterprises is a complex multiobjective decision-making problem, restricted by many factors such as purchase price, purchase quality, product delay quantity, product complaint quantity, and supplier supply capacity. Therefore, shipbuilding enterprises should comprehensively consider the various decisions that affect the order allocation so as to maximize the benefits.

The supplier selection problem of shipbuilding enterprises is an uncertain fuzzy multicriteria decision-making
(MCDM) problem. In practice, due to the complexity of shipbuilding enterprise problems, the limitations of decision-makers' knowledge, the fuzziness of information of alternative suppliers, and the high cost of obtaining the accurate information of shipbuilding enterprises, many criteria decision-making problems are often accompanied by many uncertainties. To solve this problem, fuzzy set and fuzzy logic are introduced to model and describe uncertain information by fuzzy number. A fuzzy set theory exists in many practical economic management decision-making problems. The fuzzy set theory proposed by Professor Zadeh in 1965 provides an effective method for dealing with ambiguity. Professor Zadeh used a single scale (i.e., degree of membership) to define fuzzy sets; that is, a single degree of membership simultaneously expresses the two opposites of fuzziness fuzzy concepts or fuzzy phenomena. This idea is based on the dichotomy; it cannot express the neutral state 
(neither support nor opposition). In 1986, Bulgarian scholar KT Atanassov proposed the concept of intuitionistic fuzzy sets. Intuitionistic fuzzy sets use two scales (degree of membership and nonsubordination) to characterize ambiguity, simultaneously expressing support, opposition, and neutrality, and can describe the natural attributes of objective phenomena in a more detailed and comprehensive manner. In view of the fluctuation of the market economy and the uncertainty of shipowner's demand, this paper proposes a new intuitionistic fuzzy multicriteria decisionmaking method based on the SWARA (stepwise weight assessment ratio analysis) and COPRAS (complex proportional assessment) method. In this paper, the intuitionistic fuzzy SWARA-COPRAS method is used for the following reasons. (1) Intuitionistic fuzzy sets are a good solution. It can express decision-makers preferences from three aspects: membership degree, nonmembership degree, and hesitation degree and can more describe the vagueness and uncertainty of the problem. (2) The method is simple, easy to understand, and easy to implement. (3) Transaction costs are low, and decision-makers have more opportunities to set standard priorities.

The contributions of this paper are as follows:

(i) Taking into account the vacillation of shipbuilding market economy and the uncertainty and diversity of shipowners' demand, the corresponding relationship between the linguistic value of expert evaluation and intuitionistic fuzzy set is established.

(ii) In the supplier index selection of shipbuilding enterprises, the risk index is included. In the selection of suppliers, most of them focus on the cost, quality, and service level and rarely take the risk into account.

(iii) The intuitionistic fuzzy SWARA-COPRAS method is established and applied to a new field: supplier selection of shipbuilding enterprises.

The structure of this article is as follows. Section 2 provides a literature review. Section 3 details the intuitionistic fuzzy multicriteria decision-making method. Section 4 introduces the framework of the intuitionistic fuzzy multicriteria method. In Section 5, a shipbuilding company based in Shanghai, China, is taken as an example and the algorithms comparative analysis and the sensitivity analysis show that the method is effective and stable. Section 6 gives the conclusions of this article.

\section{Literature Review}

2.1. Supplier Management in Shipbuilding Enterprises. In the era of information digitization, the essence of the need for communication between enterprises and timely exchange of demand information drives a new mode of cooperation, namely, supply chain management (SCM). With the rapid development of global economic integration and the increasing external competition environment of shipbuilding enterprises, the global market competition is becoming more and more intense, and SCM has become an important means for shipbuilding enterprises to improve their core competition. Compared with other manufacturing industries, shipbuilding enterprise supply chain management has its own uniqueness. Shipbuilding has the characteristics of custom production. The main impetus of creation comes from the end-client transport proprietor, which is the genuine interest chain of ship pulling. There are many cooperative enterprises in the whole supply chain node; through mutual cooperation, the whole shipbuilding supply chain management process can be completed.

The supply chain management process of shipbuilding ventures with center shipbuilding endeavors as the principle body is firmly identified with the necessities of shipowners and furthermore includes different materials and hardware and their providers. Shipbuilding is a typical large-scale manufacturing and assembly industry of on-demand production. The materials and resources required range from supporting equipment, plates, and profiles to coatings, cement, and cabin furniture. Its suppliers are all over the world, and the number can reach thousands, and the materials or equipment provided by these suppliers for shipbuilding enterprises directly affect the structural design and production schedule of ship products. As a result, changes in essential design, technology, and schedule information in the shipbuilding process must be communicated to key suppliers in a timely manner, giving them enough time to alter supply times and inventory levels, avoiding resource loss due to cost increases. In addition, shipowners will also propose to the core shipbuilding enterprises to supply to the designated suppliers, which requires the core shipbuilding enterprises to establish a good communication environment between shipowners and suppliers to ensure the mutual benefit of the three parties.

\subsection{Shipbuilding Enterprise Supplier Selection Method.} Related research shows that an important part of establishing win-win SCM is to choose agile, competitive, and compatible partners, namely, suppliers. The problem of supplier selection for shipbuilding enterprises is one of the main problems of shipbuilding supply chain management. At present, the methods for supplier selection can be roughly divided into four categories [1]. (1) Multiattribute decisionmaking methods include analytic hierarchy process, prioritize the organization of ranking improvement evaluation method, network analysis method, and approximate ideal solution sorting method (TOPSIS). (2) Mathematical programming model includes stochastic planning, goal planning, nonlinear programming, data envelopment analysis (DEA), linear programming, and multiobjective planning. (3) Artificial intelligence technology includes genetic algorithm, grey system theory, neural network, rough set theory, case-based reasoning (CBR), particle swarm algorithm, ant colony algorithm, and fuzzy set theory (FTS). (4) Combination (mixed) model includes $\mathrm{AHP}+\mathrm{GP}, \mathrm{AHP}+\mathrm{LP}$, AHP + FTS, and DEA + MOP. Avelina et al. [2] studied the particle swarm optimization (PSO) algorithm and differential evolution (DE) algorithm for supplier selection and order quantity allocation decision-making problems. 
Krichanchai and MacCarthy [3] studied the needs of enterprises to select suppliers to manage inventory. The indicators for selecting suppliers indicate that high-quality suppliers can bring greater benefits to the enterprise. Irmayanti [4] applied the analytic hierarchy process (AHP) method to deal with such problems in response to the fact that it is difficult for raw material suppliers to make decisions. Sadrian and Yoon [5] and Pan [6] studied the singleobjective linear programming model's supplier selection problem for the uncertain demand of suppliers. Literature [7-9] proposed that when constructing the evaluation index system, criteria such as product design and improvement of product sustainability should be considered. Literature [10-12] proposed that flexibility criteria should be used when selecting suppliers, flexibility in response to changes in orders, and uncertain demand. Mummalaneni et al. [13] aimed at the high-quality cooperative relationship of enterprise suppliers and proposed that buyers and sellers strengthen relationship building. Chen et al. [14] established a fuzzy multiattribute supplier selection model based on the triangular fuzzy set theory. Cakar and Cavus [15] used fuzzy TOPSIS to select the best dairy supplier. Chakraborty et al. [16] studied the application of the D-MARCOS method in supplier selection of the sustainable supply chain management system. Zavadskas et al. [17] used the FAHP method to study the purchasing suppliers of materials needed for the production of preinsulated pipes.

Previous research is often carried out in a deterministic environment, considering the supplier's supply capacity, delivery date, inventory, and other constraints as a known quantity. At the same time, the complexity and uncertainty of the supplier are not considered, and the potential risks of the supplier are ignored which is inconsistent with the actual situation. Most of the above methods stay in the theoretical stage and have not been put into practice. Based on the conditions during the internship period in a shipbuilding company in Shanghai, China, and on the basis of actual research, we compared the existing supplier selection methods and aimed to choose the right one. Table 1 shows the characteristics of each method.

Due to the extremely complexity and uncertainty of shipbuilding suppliers and the lack of knowledge or data in this field, it is difficult to evaluate them with accurate numbers. So, intuitionistic fuzzy numbers are used to represent fuzziness and uncertainty. Based on this, on the basis of the practical investigation of shipbuilding enterprises during the internship of shipbuilding enterprises, according to the knowledge and experience and the actual needs of supplier evaluation in shipbuilding enterprises, the transformation relationship between linguistic variable value and intuitionistic fuzzy set is established. At the same time, a hybrid method, namely, SWARA and COPRAS, is used to select shipbuilding suppliers. The weight of the supplier index is determined by using the intuitionistic fuzzy SWARA method. The ranking of suppliers is determined by the intuitionistic fuzzy COPRAS method. The method considers all kinds of uncertainties and evaluates the utility and cost indicators of alternative suppliers. Finally, the effectiveness and stability of the method are proved by comparison and sensitivity analysis. Therefore, this method is suitable for shipbuilding enterprises.

\section{The Intuitionistic Fuzzy Multicriteria Decision-Making Method}

\subsection{Intuitionistic Fuzzy Sets}

Definition 1 (see [18]). Let $X$ be a nonempty set, given a mapping.

$$
\begin{aligned}
f_{A}: X & \longrightarrow[0,1] \times[0,1], \\
x & \mapsto\left(\mu_{A}(x), \nu_{A}(x)\right) .
\end{aligned}
$$

Among them, $0 \leq \mu_{A}(x)+v_{A}(x) \leq 1, f_{A}$ determines an intuitionistic fuzzy set of nonempty set $X$, denoted as $A=$ $\left\{\left\langle x, \mu_{A}(x), \nu_{A}(x)\right\rangle \mid x \in X\right\}$ where $\mu_{A}(x)$ is a membership function, representing the membership degree of $x$ to intuitionistic fuzzy sets $A$ and $v_{A}(x)$ is the nonmembership function representing the nonmembership degree of $x$ to intuitionistic fuzzy sets $A$. Let $\pi_{A}(x)=1-\mu_{A}(x)-v_{A}(x)$, where $\pi_{A}(x)$ denotes the degree of hesitation or uncertainty. Therefore, the intuitionistic fuzzy number can also be denoted as $\left(\mu_{x}, v_{x}, \pi_{x}\right)$, and in this paper, they are denoted as $\left(\mu_{x}, v_{x}\right)$.

Definition 2 (see [19]). For intuitionistic fuzzy numbers $\alpha=(\mu, \nu)$, its score function and accuracy function are defined as

$$
\begin{aligned}
S(\alpha) & =\mu-\nu, \\
H(\alpha) & =\mu+\nu .
\end{aligned}
$$

Among them, $S(\alpha) \in[-1,1]$ and $H(\alpha) \in[0,1]$.

Definition 3 (see [20]). The score function and function of Definition 2 are improved. For an intuitionistic fuzzy number $\alpha=(\mu, \nu)$, the improved score function and accuracy function are as follows:

$$
\begin{aligned}
S^{*}(\alpha) & =\frac{S(\alpha)+1}{2}, \\
H^{*}(\alpha) & =\frac{\mu+\nu}{2} .
\end{aligned}
$$

Now, $S^{*}(\alpha) \in[0,1]$ and $H^{*}(\alpha) \in[0,1]$.

Definition 4. Let $\alpha_{j}=\left(\mu_{j}, v_{j}\right)(j=1,2, \ldots, n)$ be a series of intuitionistic fuzzy numbers, $\omega=\left(\omega_{1}, \omega_{2}, \ldots, \omega_{n}\right)^{T}$ for the corresponding weight vector, and $\sum_{j=1}^{n} \omega_{j}=1, \omega_{j} \in[0,1]$. Then, the algorithm formula of the intuitionistic fuzzy weighted average (IFWA) operator is as follows: 
TABLE 1: Comparison of supplier selection methods.

\begin{tabular}{|c|c|}
\hline Method & Features \\
\hline Analytic hierarchy process (AHP) & $\begin{array}{l}\text { Simple and practical, qualitative, and quantitative combination, but more indicators easily lead to an } \\
\text { increase in the amount of calculation }\end{array}$ \\
\hline BP neural network method & Strong nonlinear mapping ability but need a large number of samples and modeling is difficult \\
\hline Fuzzy set theory and method & $\begin{array}{c}\text { The certainty of fuzzy problem is helpful to understand the uncertainty problem and has strong } \\
\text { subjectivity }\end{array}$ \\
\hline Network analysis method (ANP) & $\begin{array}{c}\text { It can reflect the dependence between hierarchies, and it is difficult to understand the relationship } \\
\text { between factors }\end{array}$ \\
\hline TOPSIS method & Full use of original data, less information loss, strong subjective factors \\
\hline $\begin{array}{l}\text { Mathematical programming } \\
\text { (MP) model }\end{array}$ & Solving single-objective and multiobjective models, more complex \\
\hline Hybrid methods & Combine a variety of methods to solve, play the advantages of each method \\
\hline
\end{tabular}

$$
\operatorname{IFWA}_{w}\left(\alpha_{1}, \alpha_{2}, \ldots, \alpha_{n}\right)=\oplus_{j=1}^{n} \omega_{j} \alpha_{j}=\left(1-\prod_{j=1}^{n}\left(1-\mu_{j}\right)^{\omega_{j}}, \prod_{j=1}^{n} \nu_{j}^{\omega_{j}}\right)
$$

3.2. Intuitionistic Fuzzy SWARA Method. The stepwise weight assessment ratio analysis (SWARA) method is a new multicriteria decision-making method for evaluating standard weights that was proposed by Kersuliene [21-24]. The SWARA method and the intuitionistic fuzzy set theory are combined to become the intuitionistic fuzzy SWARA method. The steps are as follows:

Step 1. Evaluation index ranking: Each decision-maker expresses the relative importance of each indicator according to the corresponding intuitionistic fuzzy number, then uses equation (4) and the weight of the decision-maker to obtain the intuitionistic fuzzy weighted arithmetic average operator of the indicator, and then uses equation (3) to find the score function $S^{*}\left(C_{j}\right)$ of the indicator. According to the score function value of each indicator, the indicators are ranked from large to small.

Step 2. The relative importance correlation coefficient of each index $s_{j}(j \geq 2)$ is determined. From the second index to the last index, the difference between the score function values of two adjacent indexes is taken as the importance correlation coefficient $s_{j}(j \geq 2)$, which is

$$
s_{j}=S^{*}\left(C_{j-1}\right)-S^{*}\left(C_{j}\right), \quad \text { among } j \geq 2 .
$$

Step 3. The comparison coefficient is calculated. The calculation formula is as follows:

$$
k_{j}= \begin{cases}1, & j=1, \\ s_{j}+1, & j>1\end{cases}
$$

Step 4. The relative weight factor is calculated. The calculation formula is as follows:

$$
q_{j}= \begin{cases}1, & j=1, \\ \frac{q_{j-1}}{k_{j}}, & j>1 .\end{cases}
$$

Step 5. The final weight factor is calculated. The calculation is as follows:

$$
\lambda_{j}=\frac{q_{j}}{\sum_{k=1}^{n} q_{k}}
$$

3.3. Intuitionistic Fuzzy COPRAS Method. The complex proportional assessment method (complex proportional assessment) that is the COPRAS method was introduced by Zavadskas et al. [25]. This method comprehensively considers different evaluation performance indicators and their corresponding weights. It combines each indicator's importance and utility to gradually make the alternative hierarchical sorting and evaluation and select the best plan from them [23,26-28]. The COPRAS method is combined with the intuitionistic fuzzy set to become the intuitionistic fuzzy COPRAS method. The steps are as follows:

Step 1. According to equation (9), an intuitionistic fuzzy decision matrix $R$ is established which is

$$
R=\left[\begin{array}{c}
r_{11}, r_{12}, \ldots, r_{1 n} \\
r_{21}, r_{22}, \ldots, r_{2 n} \\
\ldots \\
r_{m 1}, r_{m 2}, \ldots, r_{m n}
\end{array}\right]
$$

$r_{i j}=\operatorname{IFWA}_{\omega}\left(z_{i j}^{(1)}, z_{i j}^{(2)}, \cdots, z_{i j}^{(p)}\right)=\omega_{1} * z_{i j}^{(1)} \oplus \omega_{2} * z_{i j}^{(2)} \oplus \cdots \oplus$ $\omega_{p} * z_{i j}^{(p)}=\left(1-\prod_{k=1}^{p}\left(1-\mu_{i j}^{(k)}\right)^{\omega_{k}}, \prod_{k=1}^{p}\left(v_{i j}^{(k)}\right)^{\omega_{k}}\right) ; \quad$ among them, $z_{i j}^{(k)}=\left(\mu_{i j}^{(k)}, v_{i j}^{(k)}\right) \cdot z_{i j}^{(k)}(k=1,2, \ldots, p)$ indicates that when the alternative $i$ corresponds to the index $j$, the intuitionistic fuzzy number is evaluated by the $k$ th expert, $m$ is the number of alternatives, and $n$ is the number of evaluation indexes. 
Step 2. Equations (4) and (9) are used to obtain the weighted intuitionistic fuzzy decision matrix $Y$, which is

$$
Y=\left[\begin{array}{c}
y_{11}, y_{12}, \ldots, y_{1 n} \\
y_{21}, y_{22}, \ldots, y_{2 n} \\
\ldots \\
y_{m 1}, y_{m 2}, \ldots, y_{m n}
\end{array}\right]
$$

Among them, $y_{i 1}=\lambda_{1} r_{i 1}=\left(1-\left(1-\mu_{r_{i 1}}\right)^{\lambda_{1}},\left(\nu_{r_{i 1}}\right)^{\lambda_{1}}\right)$, $\ldots, \quad y_{\text {in }}=\lambda_{n} r_{n}=\left(1-\left(1-\mu_{r_{i n}}\right)^{\lambda_{n}},\left(\nu_{r_{i n}}\right)^{\lambda_{n}}\right), \quad i \in\{1,2$, $\ldots, m\}$

Step 3. The sum of the benefit index and cost index is calculated. The number of indexes is $n$, order $T_{1}=$ $\{1,2, \ldots, e\}$ shows benefit index set, $T_{2}=\{e+1, e+2, \ldots, n\}$ represents a set of cost indicators, and then

$$
\begin{aligned}
& \beta_{+i}=\bigoplus_{j=1}^{e} y_{i j}^{+}, \quad i=\{1,2, \ldots, m\}, \\
& \beta_{-i}=\bigoplus_{j=e+1}^{n} y_{i j}^{-}, \quad i=\{1,2, \ldots, m\},
\end{aligned}
$$

where $y_{i j}^{+}$indicates the benefit index value and $y_{i j}^{-}$ represents the cost indicator value.

Step 4. The relative importance value $Q_{i}(i=1,2, \ldots, m)$ of each alternative is calculated, and the calculation formula is as follows:

$$
Q_{i}=S^{*}\left(\beta_{+i}\right)+\frac{S_{\min } * \sum_{i=1}^{m} S^{*}\left(\beta_{-i}\right)}{S^{*}\left(\beta_{-i}\right) \sum_{i=1}^{m}\left(S_{\min } / S^{*}\left(\beta_{-i}\right)\right)} .
$$

Among them, $S_{\min }=\min _{i} S^{*}\left(\beta_{-i}\right), S^{*}\left(\beta_{+i}\right)$ is the score function value of $\beta_{+i}$ and $S^{*}\left(\beta_{-i}\right)$ is the score function value of $\beta_{-i}$.

Step 5. The utility degree value $N_{i}$ of each alternative is calculated as follows:

$$
N_{i}=\frac{Q_{i}}{Q_{\max }} \times 100 \%, \quad i=1,2, \ldots, m,
$$

where $Q_{\max }=\operatorname{Max}_{i} Q_{i}$. According to the standard that $N_{i}$ of $Q_{\max }$ is $100 \%$, the corresponding utility degree of suppliers of other shipbuilding enterprises is calculated. The suppliers of shipbuilding enterprises are ranked according to $N_{i}$ value from high to low. The higher value of $N_{i}$ represents the ideal alternative.

\section{Proposed Research Frameworks for Alternative Supplier}

Because of the fluctuation of the market economy and the uncertainty and diversification of shipowners' demand, this article discusses supplier selection for shipbuilding enterprises from the perspective of intuitionistic fuzzy sets. Intuitionistic fuzzy set can express the preference of decision-makers from membership, nonmembership, and hesitation. It can better describe the shipbuilding company's supplier selection problem's ambiguity and uncertainty. An intuitionistic fuzzy multicriteria decision-making method framework is proposed to select shipbuilding enterprise suppliers. This framework consists of 3 phases as follows:

Phase 1. Decision-makers, alternative suppliers, and evaluation indicators are determined.

The set of alternatives is $A=\left\{A_{1}, A_{2}, \ldots, A_{m}\right\}$, the set of evaluation indicators is $C=\left\{C_{1}, C_{2}, \ldots, C_{n}\right\}$, and the corresponding weight vector is $\lambda=\left(\lambda_{1}, \lambda_{2}, \ldots, \lambda_{n}\right)^{T}$. The experts invited to evaluate alternative suppliers are $E=\left\{E_{1}, E_{2}, \ldots, E_{p}\right\}$, and the corresponding weight vector is $\omega=\left(\omega_{1}, \omega_{2}, \ldots, \omega_{p}\right)^{T}$. Different weights are assigned to each expert's evaluation results based on their educational background, position, and years of experience.

Phase 2. The weight of the evaluation index is determined.

In many MCDM problems, one of the most critical problems is to determine the weight of the evaluation index. SWARA is a new weight extraction method introduced by et al. [24]. Compared with other effective weight evaluation methods based on the pairwise comparison, such as AHP or analytic network process (ANP), this method is neither complex nor time-consuming, and it does not need to evaluate the ranking criteria too much. Decision-makers are easy to participate in the weight determination process. Each decision-maker expresses his preference for the evaluation index according to the corresponding intuitionistic fuzzy number and then uses expert weight and intuitionistic fuzzy weighted arithmetic average operator to synthesize each evaluation index's importance. Finally, the score function value of the intuitionistic fuzzy number corresponding to each evaluation index is calculated. According to each index's score function value, the weight of each index is determined. The weight of the index is further applied to the intuitionistic fuzzy COPRAS method to rank the alternatives.

Phase 3. The best shipbuilding enterprise supplier is chosen.

For the multi-index decision-making problem of shipbuilding enterprises, there is a dimensional inconsistency between indicators. Each indicator does not have a unified measurement standard, so it is difficult to compare, and there are contradictions between goals. It is precisely because of the contradiction and dimensional inconsistency between multiple indicators in the multi-index decision-making problem. Multiple indicators cannot be merged into a single indicator. Therefore, in the process of decision analysis, decision makers need to consider a series of contradictory and interrelated indicators and select the best option from the alternatives by using multi-indicator decision-making method. In this paper, a new multi-index comprehensive evaluation method, namely, the intuitionistic fuzzy COPRAS method, is used to determine the ranking of alternative suppliers and select the best shipbuilding supplier. Figure 1 shows the flow chart of the intuitionistic fuzzy multicriteria decision-making framework. 


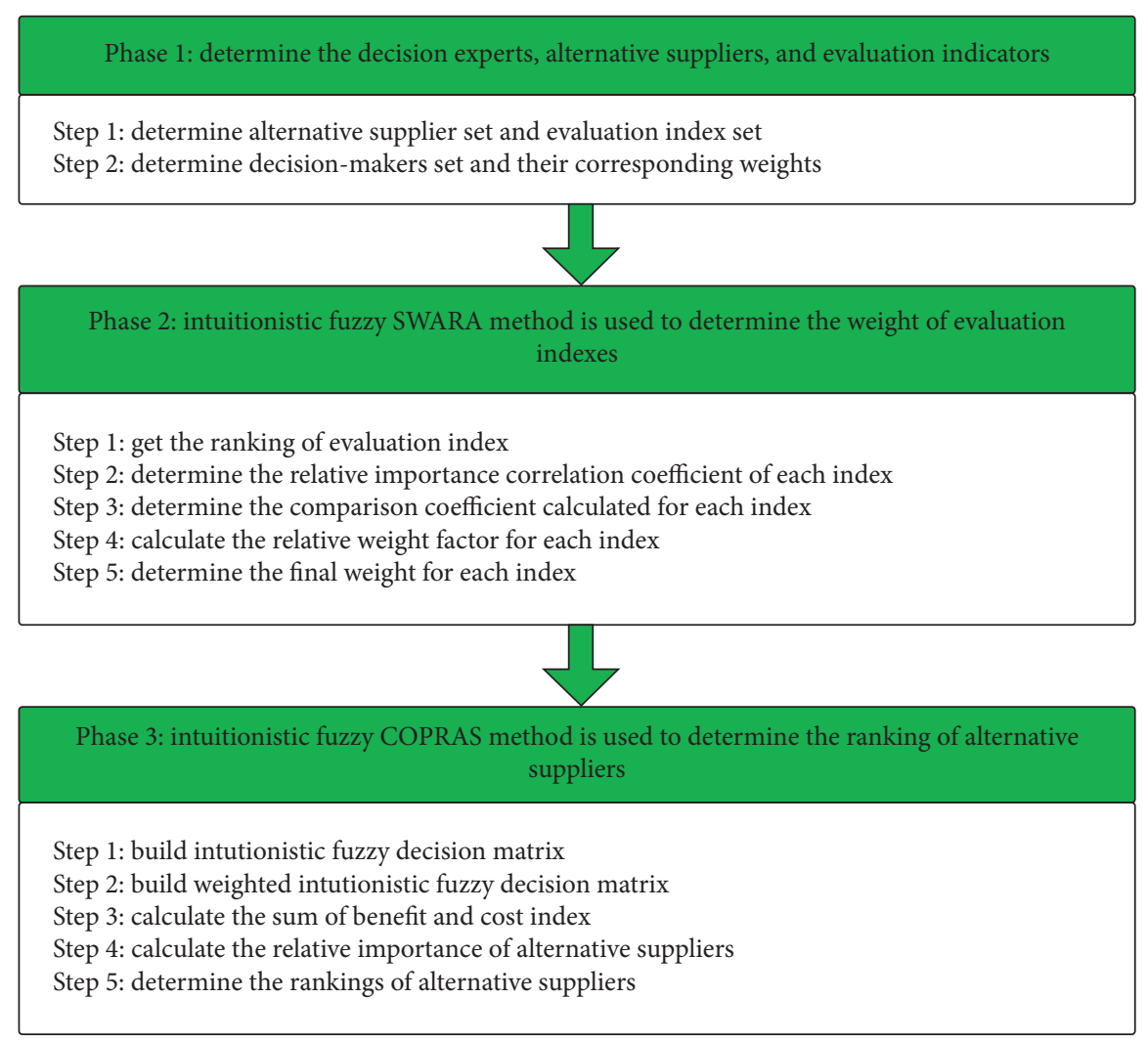

FIGURE 1: Flow chart of the intuitionistic fuzzy multicriteria decision-making framework.

\section{Case Analysis}

5.1. Problem Description. The case study of this paper is a shipyard located in Shanghai, China. On the basis of practice investigation in shipbuilding enterprises, it is found that shipbuilding enterprises need many outfitting parts, paint, welding materials, and mechanical and electrical materials, and there are also many suppliers to choose from. After ranking candidate suppliers, different suppliers still have different supply capabilities, such as product price, product quality, delivery date, and service level. According to the actual situation of shipbuilding enterprises, the selection of suppliers can be considered from the following five aspects:

(1) Price and Cost. The purchasing cost is the highest cost of shipbuilding enterprises. Shipbuilding enterprises choose more suppliers and purchase more products. Therefore, in supplier purchasing management, purchasing cost is generally strictly controlled. Price and cost generally include the product price, freight cost, and tariff if they are overseas suppliers.

(2) Quality and Technology. To preserve the safety of the finished goods and their longevity after long-term usage, the ship's quality demands exquisite shipyard manufacturing and high-quality supporting items from suppliers.

(3) Response Speed and Supply Capacity. In the shipbuilding supply chain, the time of each link should be strictly controlled, and the materials can be delivered on time according to the predetermined schedule. If the supplier's product quantity is delayed too much, it will lead to a shortage of a part, which may cause the whole production line to stop and affect the production efficiency.

(4) Service Level. Suppliers provide good service to customers, especially in the procurement process of communication. In the process of shipbuilding, the supplier's speed and attitude in dealing with the problems of equipment installation and commissioning and the timeliness of after-sales service after ship delivery all belong to the service category. The supplier provides good service for customers, especially the communication in the procurement process.

(5) Level of Risk. Because of the increase in uncertainty, the risk level must also be considered. It mainly includes supplier cooperation risk and capital risk. If it is an overseas supplier, it also includes the supplier's geographical location's economic and political stability.

This research study uses shipbuilding enterprises that want to buy the same type of steel as an example. The shipyard selects three experienced decision-makers from the department to evaluate steel suppliers. All of them have been engaged in supplier management of shipbuilding enterprises for more than 10 years. Therefore, the set of decision-makers 
is $E=\left\{E_{1}, E_{2}, E_{3}\right\}$. After the evaluation of suppliers by the three decision-makers, there are still five alternative steel suppliers, and the set of alternative suppliers is $A=\left(A_{1}, A_{2}, A_{3}, A_{4}, A_{5}\right)$. The set of supplier evaluation indexes is $C=\left\{C_{1}, C_{2}, C_{3}, C_{4}, C_{5}\right\}, C_{1}$ represents quality and technology level, $C_{2}$ represents service level, $C_{3}$ represents response speed and supply capacity, $C_{4}$ represents risk level, and $C_{5}$ represents price and cost. Among them, $C_{1}, C_{2}$, and $\mathrm{C}_{3}$ are benefit indicators, and $\mathrm{C} 4$ and $\mathrm{C} 5$ are cost indicators where the larger the index value of benefit indicators is better, and the smaller the index value of cost indicator is better. A management questionnaire about benefit type and cost type is established based on these five standards. To verify the management questionnaire's scientific validity and independence, three experienced decision-makers are provided the questionnaires separately to avoid being influenced by other experts when scoring. When evaluating the types of benefit and cost indicators, each expert gives their opinions on shipbuilding enterprise suppliers' selection criteria according to their expertise, experience, judgment, and relevant knowledge. The management questionnaire is based on the statements in Tables 2 and 3.

\subsection{Algorithm Results}

Phase 1. Decision-makers, alternative suppliers, and evaluation indicators are determined.

It can be seen from the above that the set of expert decision-makers is $E=\left\{E_{1}, E_{2}, E_{3}\right\}$, the set of alternative suppliers is $A=\left\{A_{1}, A_{2}, A_{3}, A_{4}, A_{5}\right\}$, and the set of evaluation indicators is $C=\left\{C_{1}, C_{2}, C_{3}, C_{4}, C_{5}\right\}$. Expert decision-makers $E$ contain 3 experts. Due to the different levels and experience of experts, in order to make the evaluation results more scientific and reasonable, different weights are given to experts according to their educational background, position, and working years. The results are shown in Table 4 . According to Table 4, the weight of the decision-makers can be obtained $\omega=\left(\omega_{1}, \omega_{2}, \omega_{3}\right)=(0.3404,0.3830$, 0.2766).

Phase 2. The weight of the evaluation index is determined.

The three decision-makers expressed their preference for indicators according to the intuitionistic fuzzy numbers in Table 2 and then obtained Table 5 according to Table 4 and equations (3) and (4). According to Table 4 , score function value $S^{*}\left(C_{j}\right)$ is obtained, which is sorted from large to small, and after that Table 6 is obtained. According to Table 6, the weight of the evaluation index can be obtained.

$$
\begin{aligned}
\lambda= & \left(\lambda_{1}, \lambda_{2}, \lambda_{3}, \lambda_{4}, \lambda_{5}\right)=(0.2159,0.1797,0.2086, \\
& 0.1619,0.2339) .
\end{aligned}
$$

Phase 3. The priority of steel suppliers is determined.

Table 7 is obtained according to Table 3 . Then, Table 8 is obtained according to equation (4) and Table 7. According to
TABLE 2: Linguistic terms for rating the importance of criteria.

\begin{tabular}{lc}
\hline Linguistic terms & IFNs \\
\hline Extremely important (EI) & $(0.90,0.05)$ \\
Very important (VI) & $(0.80,0.15)$ \\
Important (I) & $(0.65,0.30)$ \\
Middle (M) & $(0.50,0.45)$ \\
Unimportant (U) & $(0.35,0.60)$ \\
Very unimportant (VU) & $(0.20,0.75)$ \\
Extremely unimportant (EU) & $(0.10,0.90)$ \\
\hline
\end{tabular}

TAвLE 3: Linguistic terms for rating the alternatives.

\begin{tabular}{lc}
\hline Linguistic terms & IFNs \\
\hline Extremely good (EG)/extremely high (EH) & $(1.00,0.00)$ \\
Very very good (VVG)/very very high (VVH) & $(0.90,0.10)$ \\
Very good (VG)/very high (VH) & $(0.80,0.10)$ \\
Good (G)/high (H) & $(0.70,0.20)$ \\
Medium good (MG)/medium high (MH) & $(0.60,0.30)$ \\
Fair (F)/medium (M) & $(0.50,0.40)$ \\
Medium bad (MB)/medium low (ML) & $(0.40,0.50)$ \\
Bad (B)/low (L) & $(0.25,0.60)$ \\
Very bad (VB)/very low (VL) & $(0.10,0.75)$ \\
Very very bad (VVB)/very very low (VVL) & $(0.10,0.90)$ \\
\hline
\end{tabular}

equations (4) and (9), the weighted intuitionistic fuzzy decision matrix is obtained, and the results are shown in Table 9. According to equations (11)-(14), we can get $S_{+i}, S_{-i}$, $Q_{i}$, and $N_{i}(\%)$, and the results are shown in Table 10 . According to the relative importance value and effect degree value of the steel suppliers in Table 10, the importance of steel alternative suppliers for shipbuilding enterprises is ranked as follows: $A_{1}>A_{3}>A_{4}>A_{5}>A_{2}$, so $A_{1}$ is the best supplier. It can be seen from Table 10 that the benefit value of $A_{1}$ ranks second, but its cost value is the lowest, so it ranks first comprehensively. The benefit value of $A_{3}$ is the second, but its cost value is high, so it is the second, which is in line with the actual situation. In order to select the best supplier, the value of the benefit index and cost index should be weighed comprehensively.

5.3. Comparative Analysis. In order to verify the effectiveness and rationality of the decision model, the fuzzy TOPSIS method [15, 29], fuzzy CoCoSo method [30], and fuzzy MOORA method [31] are applied to the decision matrix (as shown in Table 9). The risk ranking results of the four methods are shown in Table 11. According to Table 11, the TOPSIS method can be seen that $A_{1}>A_{3}>A_{5}>A_{4}>A_{2}$ and the rest are $A_{1}>A_{3}>A_{4}>A_{5}>A_{2}$, which shows the effectiveness of this method.

5.4. Sensitivity Analysis. It can be seen from the above that there are five evaluation indexes for shipbuilding enterprises to select steel suppliers: quality and technical level $\left(C_{1}\right)$, service level $\left(C_{2}\right)$, response time and supply capacity $\left(C_{3}\right)$, risk level $\left(C_{4}\right)$, and price and cost $\left(C_{5}\right)$. In this section, by exchanging each evaluation index's weight with the weight of another evaluation index, the weight of other evaluation 
TABLE 4: The relative importance and weight value of decision-makers.

\begin{tabular}{lcccc}
\hline No. & Working years & Education level & Position & Weights \\
\hline Expert 1 & 21 & MSc & Deputy minister & 0.3404 \\
Expert 2 & 15 & PhD & Minister & 0.3830 \\
Expert 3 & 26 & BS & Steel plate team leader & 0.2766 \\
\hline
\end{tabular}

TABLE 5: Index importance and its score function values.

\begin{tabular}{lccccc}
\hline Index & $E_{1}$ & $E_{2}$ & $E_{3}$ & Aggregated IFNs & Score function value $S^{*}\left(C_{j}\right)$ \\
\hline$C_{1}$ & $\mathrm{VI}$ & $\mathrm{I}$ & $\mathrm{VI}$ & $(0.7522,0.1956)$ & 0.7783 \\
$C_{2}$ & $\mathrm{I}$ & $\mathrm{M}$ & $(0.5572,0.3920)$ & 0.5826 \\
$C_{3}$ & $\mathrm{I}$ & $\mathrm{VI}$ & $\mathrm{I}$ & $(0.7175,0.2301)$ & 0.7437 \\
$C_{4}$ & $\mathrm{M}$ & $\mathrm{U}$ & $(0.4471,0.5024)$ & 0.4724 \\
$C_{5}$ & $\mathrm{VI}$ & $\mathrm{VI}$ & $\mathrm{EI}$ & $(0.8349,0.1107)$ & 0.8621 \\
\hline
\end{tabular}

TABLE 6: Weight values obtained by the intuitionistic fuzzy SWARA method.

\begin{tabular}{|c|c|c|c|c|c|}
\hline Index & & $s_{j}$ & $k_{j}$ & $q_{j}$ & $\lambda_{j}$ \\
\hline$C_{5}$ & 0.8621 & - & 1 & 1 & 0.2339 \\
\hline$C_{1}$ & 0.7783 & 0.0838 & 1.0838 & 0.9227 & 0.2159 \\
\hline$C_{3}$ & 0.7437 & 0.0346 & 1.0346 & 0.8918 & 0.2086 \\
\hline$C_{2}$ & 0.5826 & 0.1611 & 1.1611 & 0.7681 & 0.1797 \\
\hline$C_{4}$ & 0.4724 & 0.1102 & 1.1102 & 0.6919 & 0.1619 \\
\hline
\end{tabular}

TABLE 7: The ratings of the alternative suppliers.

\begin{tabular}{lccccccccccccccc}
\hline Supplier & & $A_{1}$ & & & $A_{2}$ & & & $A_{3}$ & & & $A_{4}$ & & $A_{5}$ \\
Expert & $E_{1}$ & $E_{2}$ & $E_{3}$ & $E_{1}$ & $E_{2}$ & $E_{3}$ & $E_{1}$ & $E_{2}$ & $E_{3}$ & $E_{1}$ & $E_{2}$ & $E_{3}$ & $E_{1}$ & $E_{2}$ & $E_{3}$ \\
\hline$C_{1}$ & $\mathrm{G}$ & $\mathrm{VG}$ & $\mathrm{G}$ & $\mathrm{MG}$ & $\mathrm{G}$ & $\mathrm{MG}$ & $\mathrm{VG}$ & $\mathrm{VVG}$ & $\mathrm{VG}$ & $\mathrm{MG}$ & $\mathrm{G}$ & $\mathrm{G}$ & $\mathrm{F}$ & $\mathrm{MG}$ & $\mathrm{MG}$ \\
$C_{2}$ & $\mathrm{MG}$ & $\mathrm{G}$ & $\mathrm{MG}$ & $\mathrm{F}$ & $\mathrm{MG}$ & $\mathrm{G}$ & $\mathrm{VG}$ & $\mathrm{G}$ & $\mathrm{VG}$ & $\mathrm{MG}$ & $\mathrm{F}$ & $\mathrm{MG}$ & $\mathrm{MG}$ & $\mathrm{MG}$ & $\mathrm{F}$ \\
$C_{3}$ & $\mathrm{VG}$ & $\mathrm{G}$ & $\mathrm{VG}$ & $\mathrm{G}$ & $\mathrm{G}$ & $\mathrm{MG}$ & $\mathrm{VG}$ & $\mathrm{VG}$ & $\mathrm{G}$ & $\mathrm{VG}$ & $\mathrm{G}$ & $\mathrm{G}$ & $\mathrm{VG}$ & $\mathrm{G}$ & $\mathrm{MG}$ \\
$C_{4}$ & $\mathrm{~L}$ & $\mathrm{~L}$ & $\mathrm{~L}$ & $\mathrm{ML}$ & $\mathrm{M}$ & $\mathrm{ML}$ & $\mathrm{VL}$ & $\mathrm{M}$ & $\mathrm{M}$ & $\mathrm{MH}$ & $\mathrm{ML}$ & $\mathrm{ML}$ & $\mathrm{M}$ & $\mathrm{ML}$ & $\mathrm{M}$ \\
$C_{5}$ & $\mathrm{ML}$ & $\mathrm{ML}$ & $\mathrm{L}$ & $\mathrm{M}$ & $\mathrm{M}$ & $\mathrm{ML}$ & $\mathrm{L}$ & $\mathrm{H}$ & $\mathrm{MH}$ & $\mathrm{MH}$ & $\mathrm{L}$ & $\mathrm{ML}$ & $\mathrm{ML}$ & $\mathrm{L}$ & $\mathrm{ML}$ \\
\hline
\end{tabular}

TABLE 8: Intuitionistic fuzzy aggregation decision matrix of steel supplier selection for shipbuilding enterprises.

\begin{tabular}{lccccc}
\hline Index & $A_{1}$ & $A_{2}$ & $A_{3}$ & $A_{4}$ & $A_{5}$ \\
\hline$C_{1}$ & $(0.7432,0.1534)$ & $(0.6417,0.2568)$ & $(0.8466,0.1000)$ & $(0.6691,0.2296)$ & $(0.5684,0.3309)$ \\
$C_{2}$ & $(0.6417,0.2568)$ & $(0.6014,0.2958)$ & $(0.7664,0.1304)$ & $(0.5643,0.3349)$ & $(0.5745,0.3248)$ \\
$C_{3}$ & $(0.7664,0.1304)$ & $(0.6752,0.2237)$ & $(0.7763,0.1211)$ & $(0.7387,0.1580)$ & $(0.7170,0.1767)$ \\
$C_{4}$ & $(0.2500,0.6000)$ & $(0.5399,0.4590)$ & $(0.3892,0.4954)$ & $(0.4774,0.4202)$ & $(0.4638,0.4357)$ \\
$C_{5}$ & $(0.3618,0.5259)$ & $(0.4741,0.4255)$ & $(0.5563,0.3252)$ & $(0.4307,0.4506)$ & $(0.3465,0.5362)$ \\
\hline
\end{tabular}

TAвLE 9: Weighted intuitionistic fuzzy aggregation decision matrix for shipbuilding enterprises to choose steel suppliers.

\begin{tabular}{lccccc}
\hline Index & $A_{1}$ & $A_{2}$ & $A_{3}$ & $A_{4}$ & $A_{5}$ \\
\hline$C_{1}$ & $(0.2543,0.6671)$ & $(0.1988,0.7457)$ & $(0.3329,0.6083)$ & $(0.2124,0.7278)$ & $(0.1659,0.7876)$ \\
$C_{2}$ & $(0.1684,0.7833)$ & $(0.1524,0.8034)$ & $(0.2300,0.6935)$ & $(0.1387,0.8216)$ & $(0.1424,0.8171)$ \\
$C_{3}$ & $(0.2616,0.6538)$ & $(0.2091,0.7317)$ & $(0.2683,0.6438)$ & $(0.2442,0.6805)$ & $(0.2315,0.6966)$ \\
$C_{4}$ & $(0.0455,0.9206)$ & $(0.1181,0.8816)$ & $(0.0767,0.8925)$ & $(0.0997,0.8690)$ & $(0.0960,0.8741)$ \\
$C_{5}$ & $(0.0997,0.8604)$ & $(0.1396,0.8188)$ & $(0.1731,0.7689)$ & $(0.1235,0.8299)$ & $(0.0947,0.8643)$ \\
\hline
\end{tabular}

indexes remains unchanged. Then, the relative importance value and utility value of alternative steel suppliers for shipbuilding enterprise are calculated $S_{1}: C_{1}-C_{2}$ is scenario 1 , which means the weight of $C_{1}$ is exchanged with that of $C_{2}$.
The weight of other indicators remains unchanged. By analogy, there are a total of 10 scenarios, namely, $S_{1}: C_{1}-C_{2}$, $S_{2}: C_{1}-C_{3}, S_{3}: C_{1}-C_{4}, S_{4}: C_{1}-C_{5}, S_{5}: C_{2}-C_{3}, S_{6}: C_{2}-C_{4}, S_{7}: C_{2}-C_{5}$, $S_{8}: C_{3}-C_{4}, S_{9}: C_{3}-C_{5}$, and $S_{10}: C_{4}-C_{5}$ In each scenario, the 
TABLE 10: Supplier evaluation results and ranking based on the intuitionistic fuzzy COPRAS method.

\begin{tabular}{lccccccc}
\hline Supplier & $\beta_{+i}$ & $S_{+i}$ & $\beta_{-i}$ & $S_{-i}$ & $Q_{i}$ & $N_{i}(\%)$ & Ranking \\
\hline$A_{1}$ & $(0.5422,0.3416)$ & 0.6003 & $(0.1407,0.7921)$ & 0.1743 & 0.9046 & 100 & 1 \\
$A_{2}$ & $(0.4628,0.4384)$ & 0.5122 & $(0.2412,0.7218)$ & 0.2597 & 0.7165 & 79.21 & 5 \\
$A_{3}$ & $(0.6241,0.2716)$ & 0.6763 & $(0.2365,0.6863)$ & 0.2751 & 0.8690 & 96.07 & 2 \\
$A_{4}$ & $(0.4873,0.4069)$ & 0.5402 & $(0.2109,0.7212)$ & 0.2448 & 0.7568 & 83.66 & 3 \\
$A_{5}$ & $(0.4503,0.4483)$ & 0.5010 & $(0.1816,0.7556)$ & 0.2130 & 0.7500 & 82.91 & 4 \\
\hline
\end{tabular}

TABLE 11: Ranking by different methods.

\begin{tabular}{lcccc}
\hline Supplier & Proposed method & TOPSIS & CoCoSo & MOORA \\
\hline$A_{1}$ & 1 & 1 & 1 & 1 \\
$A_{2}$ & 5 & 5 & 5 & 2 \\
$A_{3}$ & 2 & 2 & 3 & 2 \\
$A_{4}$ & 3 & 4 & 4 & 3 \\
$A_{5}$ & 4 & 3 & 4 \\
\hline
\end{tabular}

TABLE 12: Sensitivity analysis of rankings by $Q_{i}$.

\begin{tabular}{|c|c|c|c|c|c|c|}
\hline Scenarios & $A_{1}$ & $A_{2}$ & $A_{3}$ & $A_{4}$ & $A_{5}$ & Sort \\
\hline$S_{1}$ & 0.8986 & 0.7143 & 0.8648 & 0.7514 & 0.7503 & $A_{1}>A_{3}>A_{4}>A_{5}>A_{2}$ \\
\hline$S_{2}$ & 0.9049 & 0.7169 & 0.8683 & 0.7578 & 0.7518 & $A_{1}>A_{3}>A_{4}>A_{5}>A_{2}$ \\
\hline$S_{3}$ & 0.9071 & 0.7065 & 0.8586 & 0.7464 & 0.7444 & $A_{1}>A_{3}>A_{4}>A_{5}>A_{2}$ \\
\hline$S_{4}$ & 0.9051 & 0.7179 & 0.8739 & 0.7577 & 0.7469 & $A_{1}>A_{3}>A_{4}>A_{5}>A_{2}$ \\
\hline$S_{5}$ & 0.8984 & 0.7131 & 0.8685 & 0.7485 & 0.7427 & $A_{1}>A_{3}>A_{4}>A_{5}>A_{2}$ \\
\hline$S_{6}$ & 0.9090 & 0.7146 & 0.8683 & 0.7564 & 0.7482 & $A_{1}>A_{3}>A_{4}>A_{5}>A_{2}$ \\
\hline$S_{7}$ & 0.8965 & 0.7168 & 0.8767 & 0.7509 & 0.7402 & $A_{1}>A_{3}>A_{4}>A_{5}>A_{2}$ \\
\hline$S_{8}$ & 0.9045 & 0.7052 & 0.8652 & 0.7411 & 0.7326 & $A_{1}>A_{3}>A_{4}>A_{5}>A_{2}$ \\
\hline$S_{9}$ & 0.9064 & 0.7198 & 0.8734 & 0.7613 & 0.7519 & $A_{1}>A_{3}>A_{4}>A_{5}>A_{2}$ \\
\hline$S_{10}$ & 0.9142 & 0.7110 & 0.8794 & 0.7488 & 0.7325 & $A_{1}>A_{3}>A_{4}>A_{5}>A_{2}$ \\
\hline
\end{tabular}

TABLE 13: Sensitivity analysis of rankings by $N_{i}(\%)$.

\begin{tabular}{|c|c|c|c|c|c|c|}
\hline Scenarios & $A_{1}$ & $A_{2}$ & $A_{3}$ & $A_{4}$ & $A_{5}$ & Sort \\
\hline$S_{1}$ & 100 & 79.49 & 96.25 & 83.63 & 83.49 & $A_{1}>A_{3}>A_{4}>A_{5}>A_{2}$ \\
\hline$S_{2}$ & 100 & 79.22 & 95.95 & 83.74 & 83.08 & $A_{1}>A_{3}>A_{4}>A_{5}>A_{2}$ \\
\hline$S_{3}$ & 100 & 77.89 & 94.66 & 82.28 & 82.07 & $A_{1}>A_{3}>A_{4}>A_{5}>A_{2}$ \\
\hline$S_{4}$ & 100 & 79.31 & 96.56 & 83.71 & 82.52 & $A_{1}>A_{3}>A_{4}>A_{5}>A_{2}$ \\
\hline$S_{5}$ & 100 & 79.38 & 96.68 & 83.32 & 82.68 & $A_{1}>A_{3}>A_{4}>A_{5}>A_{2}$ \\
\hline$S_{6}$ & 100 & 78.62 & 95.52 & 83.21 & 82.31 & $A_{1}>A_{3}>A_{4}>A_{5}>A_{2}$ \\
\hline$S_{7}$ & 100 & 79.95 & 97.79 & 83.75 & 82.56 & $A_{1}>A_{3}>A_{4}>A_{5}>A_{2}$ \\
\hline$S_{8}$ & 100 & 77.96 & 95.66 & 81.93 & 80.99 & $A_{1}>A_{3}>A_{4}>A_{5}>A_{2}$ \\
\hline$S_{9}$ & 100 & 79.41 & 93.36 & 83.99 & 82.95 & $A_{1}>A_{3}>A_{4}>A_{5}>A_{2}$ \\
\hline$S_{10}$ & 100 & 77.78 & 96.20 & 81.90 & 80.12 & $A_{1}>A_{3}>A_{4}>A_{5}>A_{2}$ \\
\hline
\end{tabular}

relative importance and utility values of each supplier are calculated. Table 12 shows the relative relevance values of the ten scenarios, whereas Table 13 shows the utility values. In every case, supplier A1 comes out on top. The supplier is sorted as $A_{1}>A_{3}>A_{4}>A_{5}>A_{2}$. Therefore, it can be concluded that the intuitionistic fuzzy set is a reliable tool to select suitable suppliers for shipbuilding enterprises, which verifies the stability and effectiveness of the method and model.

\section{Conclusion}

In recent years, shipbuilding companies' selection of the most suitable suppliers has become an essential issue in shipbuilding sustainable supply chain management. Supplier selection is a complex problem and issue for shipbuilding companies due to multi-index criteria and increase in uncertain information, which is called uncertain multicriteria decision-making (MCDM) problem. A multicriteria 
decision-making method based on the intuitionistic fuzzy SWARA-COPRAS method is proposed to solve this problem. This method has not been used to solve the problem of supplier selection in shipbuilding enterprises. Intuitionistic fuzzy sets are an excellent way to deal with the uncertainty of shipbuilding companies' suppliers. Intuitionistic fuzzy numbers can be obtained from degrees of membership, nonmembership, and hesitation, which represent decisionmakers' preferences and better characterize the problem's ambiguity and ambiguity. Decision-makers' weight is decided objectively based on their skill, experience, judgment, and related knowledge, which is closer to the truth of the decision-making situation. The intuitionistic fuzzy SWARA approach is used to determine the weights of the five indicators chosen by the shipbuilding company's suppliers. The intuitionistic fuzzy COPRAS approach is used to rank and evaluate the relative importance of different shipbuilding companies, with the best one being chosen. Finally, the example of shipbuilding enterprise of steel supplier based in Shanghai, China, is considered, and the steel suppliers' ranking is determined.

Although the intuitionistic fuzzy multicriterion decision-making method has piqued the interest of academics both at home and abroad and has yielded some results, its study is still in its infancy and requires more development and promotion. In the future research, we can focus on the following directions. First of all, the SWARA method has some limitations in determining the weight of supplier indicators. It is based on actual data and has a high level of subjectivity; thus, it can be included in the subjective weighting. At the same time, the objective weight is introduced. If the data authenticity is high, the subjective weight is given a higher value. If it cannot be determined, it can take 0.5 . Secondly, in sensitivity analysis, some standard methodologies can be used to change the weight so as to test the effectiveness and sensitivity of the method. Last, the intuitionistic fuzzy multicriteria decision-making method can consider intuitionistic triangular fuzzy number, intuitionistic trapezoidal fuzzy number, and the bipolar fuzzy sets to represent the fuzziness and uncertainty. At the same time, it can be combined with other MCDM methods to compare with the results of this paper.

\section{Data Availability}

The data used to support this study are included within the article as Tables 2 to 13 .

\section{Conflicts of Interest}

The authors declare that they have no conflicts of interest.

\section{References}

[1] J. Chai, J. N. K. Liu, and E. W. T. Ngai, "Application of decision-making techniques in supplier selection: a systematic review of literature," Expert Systems with Applications, vol. 40, no. 10 , pp. $3872-3885,2013$.

[2] A. Reyes Avelina, M. Abraham, and O. B. Elias, "A heuristic method for the supplier selection and order quantity allocation problem," Applied Mathematical Modelling, vol. 90, no. 2, pp. 1130-1142, 2021.

[3] S. Krichanchai and B. L. MacCarthy, "The adoption of vendor managed inventory for hospital pharmaceutical supply," The International Journal of Logistics Management, vol. 28, no. 3, pp. 755-780, 2017.

[4] H. Irmayanti, "Raw material supplier selection with analytics hierarchy process (AHP) method," IOP Conference Series: Materials Science and Engineering, vol. 879, no. 1, Article ID 012048, 2020.

[5] A. A. Sadrian and Y. S. Yoon, "A procurement decision support system in business volume discount environments," Operations Research, vol. 42, no. 1, pp. 14-23, 1994.

[6] A. C. Pan, "Allocation of order quantities among suppliers," Journal of Purchasing and Materials Management, vol. 25, no. 2, pp. 36-39, 1989.

[7] S. C. Ting and I. ChoD, "An integrated approach for supplier selection and purchasing decisions," Supply Chain Management: An International Journal.vol. 13, no. 2, pp. 116-127, 2007.

[8] F. T. S. Chan and N. Kumar, "Global supplier development considering risk factors using fuzzy extended AHP-based approach," Omega, vol. 35, no. 4, pp. 417-431, 2007.

[9] H. Fazlollahtabar and N. Kazemitash, "Green supplier selection based on the information system performance evaluation using the integrated best-worst method," Facta Universitatis, Series: Mechanical Engineering, 2021.

[10] S. Chopra and P. Meindl, Supply Chain Management: Strategy, Planning, and Operation, Pearson/Prentice Hall, Hoboken, NJ, USA, Global edition, 2001.

[11] M. Kumar, P. Vrat, and R. Shankar, "A fuzzy goal programming approach for vendor selection problem in a supply chain," Computers \& Industrial Engineering, vol. 46, no. 1, pp. 69-85, 2003.

[12] R. Verma and M. E. Pullman, "An analysis of the supplier selection process,” Omega, vol. 26, no. 6, pp. 739-750, 1998.

[13] V. Mummalaneni, K. M. Dubas, and C. N. Chiang-nan Chao, "Chinese purchasing managers' preferences and trade-offs in supplier selection and performance evaluation," Industrial Marketing Management, vol. 25, no. 2, pp. 115-124, 1996.

[14] C.-T. Chen, C.-T. Lin, and S.-F. Huang, "A fuzzy approach for supplier evaluation and selection in supply chain management," International Journal of Production Economics, vol. 102, no. 2, pp. 289-301, 2006.

[15] T. Cakar and B. Çavuş, "Supplier selection process in dairy industry using fuzzy-topsis method," Operational Research in Engineering Sciences: Theory and Applications, vol. 4, no. 1, pp. 82-98, 2021.

[16] S. Chakraborty, R. Chattopadhyay, and S. Chakraborty, "An integrated D-MARCOS method for supplier selection in an iron and steel industry," Decision Making: Applications in Management and Engineering, vol. 3, no. 2, pp. 49-69, 2020.

[17] E. K. Zavadskas, Z. Turskis, Ž. Stević, and A. Mardani, "Modelling procedure for the selection of steel pipes supplier by applying fuzzy AHP method," Operational Research in Engineering Sciences: Theory and Applications, vol. 3, no. 2, pp. 39-53, 2020.

[18] K. T. Atanassov, "More on intuitionistic fuzzy sets," Fuzzy Sets and Systems, vol. 33, no. 1, pp. 37-45, 1989.

[19] Z. Xu, "Methods for aggregating interval-valued intuitionistic fuzzy information and their application to decision making," Control and Decision, vol. 22, no. 2, pp. 215-219, 2007.

[20] G.-L. Xu, S.-P. Wan, and X.-L. Xie, "A selection method based on MAGDM with interval-valued intuitionistic fuzzy sets," 
Mathematical Problems in Engineering, vol. 2015, Article ID 791204, 13 pages, 2015.

[21] C. Liu, "Supplier selection evaluation of shipbuilding enterprises based on entropy weight and multi-attribute decision making," Proceedings of the Fifth International Forum on Decision Sciences, pp. 255-268, Springer, Berlin, Germany, 2018.

[22] J. Qin, X. Liu, and W. Pedrycz, "An extended TODIM multicriteria group decision making method for green supplier selection in interval type-2 fuzzy environment," European Journal of Operational Research, vol. 258, no. 2, pp. 626-638, 2017.

[23] N. Zarbakhshnia, H. Soleimani, and H. Ghaderi, "Sustainable third-party reverse logistics provider evaluation and selection using fuzzy SWARA and developed fuzzy COPRAS in the presence of risk criteria," Applied Soft Computing, vol. 65, no. 1, pp. 307-319, 2018.

[24] V. Keršuliene, E. K. Zavadskas, and Z. Turskis, "Selection of rational dispute resolution method by applying new step-wise weight assessment ratio analysis (SWARA)/racionalaus gincu sprendimo budo nustatymas taikant nauja kriteriju svoriu nustatymo metoda, pagrista nuosekliu laipsnisku poriniu kriteriju," Journal of Business Economics and Management, vol. 11, no. 2, pp. 243-258, 2010.

[25] E. K. Zavadskas, Z. Turskis, and J. Tamošaitienè, "Multicriteria selection of project managers by applying grey criteria/ projektų valdytojo parinkimo daugiatikslio vertinimo modelis," Technological and Economic Development of Economy, vol. 14, no. 4, pp. 462-477, 2008.

[26] A. Roozbahani, H. Ghased, and M. Hashemy Shahedany, "Inter-basin water transfer planning with grey COPRAS and fuzzy COPRAS techniques: a case study in Iranian Central Plateau," Science of the Total Environment, vol. 726, no. 7, Article ID 138499, 2020.

[27] Y. Zheng, Z. Xu, Y. He, and H. Liao, "Severity assessment of chronic obstructive pulmonary disease based on hesitant fuzzy linguistic COPRAS method," Applied Soft Computing, vol. 69, no. 1, pp. 60-71, 2018.

[28] D. Schitea, M. Deveci, M. Iordache, K. Bilgili, I. Z. Iordache, and I. Iordache, "Hydrogen mobility roll-up site selection using intuitionistic fuzzy sets based WASPAS, COPRAS and EDAS," International Journal of Hydrogen Energy, vol. 44, no. 16, pp. 8585-8600, 2019.

[29] M. Gul and M. F. Ak, "A comparative outline for quantifying risk ratings in occupational health and safety risk assessment," Journal of Cleaner Production, vol. 196, no. 9, pp. 653-664, 2018.

[30] U. Alptekin, K. C. Bülent, and A. Topal, "Location selection for logistics center with fuzzy SWARA and CoCoSo methods," Journal of Intelligent \& Fuzzy Systems, vol. 38, no. 4, pp. 4693-4709, 2020.

[31] D. Rahim and Y. Samuel, "A hybrid decision-making approach based on FCM and MOORA for occupational health and safety risk analysis," Journal of Safety Research, vol. 71, no. 12, pp. 111-123, 2019. 